\title{
Atualidade da teologia da cultura de Paul Tillich ${ }^{1}$
}

\author{
Etienne Alfred Higuet ${ }^{2}$
}

\section{RESUMO}

A teologia de Tillich elaborou-se como um constante diálogo e confronto com os movimentos sociais, políticos, filosóficos, científicos e artísticos do século XX, no afinco de descobrir sua dimensão religiosa suprema, suas chances e seus desvios, suas exigências e seus apelos. Foi nessa intenção que Tillich construiu o "método de correlação" que o tornou famoso. É nesse sentido que toda a teologia dele pode ser qualificada de "teologia da cultura". O breve trabalho que aqui propomos explicitará numa primeira parte os principais conceitos que estruturam a teologia da cultura de Tillich : preocupação suprema, última ou incondicional; duplo conceito de religião; profanização e demonização; cultura e estilo; kairos e teonomia; princípio protestante. Apresentamos na segunda parte três aplicações, para ilustrar o projeto tillichiano de teologia da cultura: análise da cultura da sociedade industrial; análise religiosa do capitalismo e do socialismo; natureza, símbolo e sacramento.

Palavras-chave: religião, cultura, Ultimate Concern, correlação, kairos, teonomia.

1 Parte deste trabalho foi apresentada como comunicação científica no congresso da SOTER (Sociedade de Teologia e Ciências da Religião), que se reuniu em Ilhéus - BA de 08 a 12 de dezembro de 1992. Artigo publicado na REB, Vol. 104, Fasc. 213, Março de 1994. Só acrescentei resumo e abstract e atualizei algumas notas. A data da publicação corresponde à fundação do Grupo de Pesquisa Paul Tillich no Programa de Pós-Graduação em Ciências da Religião da Universidade Metodista de São Paulo, e da Sociedade Paul Tillich do Brasil. O artigo vale como testemunho desse esforço de atualização do pensamento de Paul Tillich, esforço que chegou em 2018 a vinte e cinco anos. Em novembro de 1993, foi organizado em São Paulo o primeiro encontro em diálogo com o pensamento de Paul Tillich. A maioria dos encontros anuais, desde então, foi dedicada à Teologia da Cultura.

2 Professor aposentado da Universidade Metodista de São Paulo, Programa de Pós-Graduação em Ciências da Religião. Foi professor visitante na Universidade Estadual do Pará e na Universidade Federal de Juiz de Fora, MG. Presidente da Associação Paul Tillich do Brasil. E.mail: etienne.higuet@.gmail.com. 


\section{ACTUALITY OF THE PAUL TILLICHS' THEOLOGY OF CULTURE}

\section{ABSTRACT}

Tillich's theology was elaborated as a constant dialogue and confrontation with the social, political, philosophical, scientific and artistic movements of the twentieth century, with the intention to discover its supreme religious dimension, their chances and deviations, their demands and their appeals. In this intention Tillich built the «correlation method» that made him famous. In this sense all his theology can be classified as «theology of culture». The brief paper we propose here will explain in a first part the main concepts that structure the Tillich's theology of culture : supreme, ultimate or unconditional concern; double concept of religion; profanization and demonization; culture and style; kairos and theonomy; protestant principle. We present in the second part three applications, to illustrate the Tillichian project of culture theology: analysis of the culture of industrial society; religious analysis of capitalism and socialism; nature, symbol and sacrament.

Key-words: religion, culture, Ultimate Concern, correlation, kairos, theonomy.

\section{Introdução}

A crise de civilização que estamos atravessando abarca os sistemas econômicos e políticos (capitalismo, socialismo, liberalismo, democracia) e os valores sociais e culturais vinculados ao grande processo histórico que já nos acostumamos a chamar de "modernidade". A figura do cristianismo que dominou o cenário ocidental desde a época da reforma protestante e católica não poderia ficar intocada. Na realidade, a tomada de consciência da crise da modernidade começa nas últimas décadas do século XIX (bastaria mencionar aqui Nietzsche, Freud, Husserl...) e cresce significativamente perante a tragédia da Primeira Guerra Mundial. A "Escola de Frankfurt" inicia um questionamento da razão instrumental como fermento dos totalitarismos. Será o fim das utopias? O fracasso da revolução alemã e o desvio estalinista da União Soviética levam a uma resposta afirmativa. Condenando os ídolos modernos, a teologia protestante da época entra no grande debate sobre o futuro 
do cristianismo no meio das "tempestades do nosso tempo"3. Como hoje, tratava-se de superar o vazio e o desencanto que sucedem a uma grande esperança. Como hoje, era preciso encarnar a fé em culturas até então desprezadas, em particular a cultura dos proletários e dos marginalizados.

Nessa perspectiva, queremos resgatar aqui o compromisso da reflexão teológica de Paul Tillich, com a superação do cristianismo burguês e o discernimento dos "valores modernos". A teologia de Tillich elaborou-se como um constante diálogo e confronto com os movimentos sociais, políticos, filosóficos, científicos e artísticos do século XX, no afinco de descobrir sua dimensão religiosa suprema, suas chances e seus desvios, suas exigências e seus apelos. Foi nessa intenção que Tillich construiu o "método de correlação" que o tornou famoso. É nesse sentido que toda a teologia dele pode ser qualificada de "teologia da cultura"4.

O breve trabalho que aqui propomos explicitará numa primeira parte os principais conceitos que estruturam a teologia da cultura de Tillich. Apresentamos na segunda parte três pequenas análises aplicativas ${ }^{5}$.

\section{Fundamentos}

Para Tillich, a religião, no sentido mais amplo da palavra, é o fato de ser tomado ou possuído por uma preocupação suprema ou incondicional (the state of being ultimately concerned/grasped by an ultimate concern).

O termo "incondicional" [...] refere-se ao elemento presente em qualquer experiência religiosa responsável pelo caráter religioso dessa experiência. Todos os símbolos religiosos do divino expressam certa afirmação incondicional. É o que se pode verificar de maneira muito acentuada no mandamento: "Amarás ao Senhor teu Deus com todo o teu coração, com

3 Título de um artigo de Paul Tilich, publicado em 1943 e retomado na coletânea $A$ Era Protestante. Ver infra, nota 4.

4 Baseamos este estudo numa coletânea de artigos publicados entre 1929 e 1942 e reunidos sob o título de The Protestant Era em 1948 (Chicago: The University of Chicago Press). Recomendamos a primorosa tradução de Jaci Maraschin que acaba de sair pelo Instituto Ecumênico de Pós-Graduação em Ciências da Religião de São Bernardo do Campo, SP, 1992. Assinalamos esse livro nas notas pela sigla EP.

5 Houve, nos anos subsequentes, da minha parte e de vários outros, apresentações mais elaboradas da teologia da cultura de Tillich no Brasil, mas preferi reproduzir o presente texto, por ser uma primeira tentativa, que se tornou quase inacessível, por ser anterior à digitalização. As aplicações da segunda parte continuam bem atuais. 
toda a tua alma e com toda a tua mente". Não se admite, nesse caso, nenhum amor parcial, restrito ou condicional a Deus. O termo "incondicionado", ou a substantivação "O Incondicional" é a abstração de ditos como o citado, que aparecem com frequência na Bíblia e na literatura religiosa clássica. Não se trata de um ser, mas de uma qualidade. Caracteriza nossa preocupação suprema e, consequentemente, incondicional, não importando se a chamarmos de "Deus", de "ser", do "bem", da "verdade" ou de qualquer outro nome. [...] Trata-se da qualidade experimentada no encontro com a realidade, por exemplo, no caráter incondicional da voz da consciência, tão lógica quanto moral ${ }^{6}$.

Observamos que o movimento parte sempre do Incondicionado, que nos "agarra" e determina toda a nossa existência.

Por outro lado, o religioso é também o ambíguo, o irracional, o equívoco, marcado pela estrutura de alienação do ser humano. Por isso, existe também a religião no sentido estrito como esfera separada de crenças e de culto, em consequência do pecado e da alienação, enquanto o Reino de Deus não vem... Daí resulta uma tendência à profanização: o ser humano institucionaliza sua religião, a transforma num fenômeno cultural e moral entre outros; e uma tendência à idolatria, à demonização, quando uma preocupação segunda é erguida ao nível da preocupação suprema, quando identifica-se o portador do sagrado com o incondicional. Nesse caso, o ser humano esquece que sua religião é apenas humana e a absolutiza, a confunde com o Incondicionado.

No que diz respeito à cultura, parece que Tillich nos dá explicitamente apenas uma definição formal, ligada ao "deciframento de seu estilo" a partir da análise das formas culturais. Do ponto de vista concreto, parece que, inicialmente, ele considerava de preferência as áreas "superiores" da produção do espírito: ciência, ética, arte, religião..., passando logo a referir-se à realidade toda enquanto recebe a marca do ser humano, a toda atividade especificamente humana e aos produtos dessa atividade - sendo que a cultura se diferencia no tempo e no espaço, produzindo a diversidade das culturas. Conforme Tillich, quem pode ler o estilo de uma cultura - ou seu poder expressivo - pode também descobrir sua preocupação suprema, sua substância religiosa.

6 EP, p. 63, nota 1. 
Tillich concebe o deciframento do estilo de uma cultura a partir de dois níveis:

1. Um nível preliminar de sentido que é o sentido direto e conscientemente visado por essa cultura e que não é habitualmente um sentido religioso (no sentido estrito). A cultura é, de fato, uma direção do espírito rumo a formas condicionadas e a uma unidade imanente de sentido - procurando ser significante em si mesma, isto é: autônoma. É uma atividade simbólica do espírito humano procurando dar um sentido ao real com o auxílio de formas lógicas; ou ainda, uma lógica do sentido, um esforço para dar uma forma racional a um conteúdo.

2. Há um outro nível de sentido, um Sentido do Sentido - o sentido último mais profundo no qual se fundamenta o sentido preliminar, imanente e formal de toda cultura, especialmente sua "unidade de sentido". Esse Sentido último não pode ser apreendido por uma análise puramente objetiva e científica: ele só é acessível a uma "percepção ou intuição imaginativa" e pressupõe uma atitude de participação pessoal e existencial no Fundamento do Sentido que é ao mesmo tempo a Realidade Última. Essa intuição imaginativa é o principal instrumento do "método de correlação" entre, de um lado, a questão do sentido que surge da nossa existência radicalmente ameaçada e alienada (individual e coletivamente), porém sempre aberta ao Infinito, Transcendente ou Incondicional - isso, sempre numa situação cultural concreta; e, de outro lado, a resposta dada pela mensagem cristã reinterpretada em função dessa situação cultural. Trata-se da irrupção do Novo Ser em Jesus como Cristo, nova realidade que, ela só, é capaz de superar a alienação e a ameaça de destruição da realidade e do sentido. O método de correlação determina assim uma reflexão teológica que será, inteiramente, uma "teologia da cultura"

Os conceitos de "kairos" e de "teonomia" (com os correlatos de "autonomia" e "heteronomia") constituem o instrumental de uma "análise religiosa da cultura". O kairos é o tempo qualitativo, cheio de sentido, de tensões, de possibilidades e de impossibilidades. No Novo Testamento, é o "tempo certo" do advento de Cristo, momento pleno de riqueza, de conteúdo e de significado. Devemos pensar no kairos em termos universais, não o limitando ao passado, mas elevando-o à categoria de princípio geral da história, também relevante para o tempo presente: os momentos de kairos são manifestações extraordinárias do

7 Ver Jean-Paul GABUS, Introduction à la théologie de la culture de Paul Tillich. Paris: PUF, 1969, p. 49ss. Esse estudo nos ajudou bastante em todo este trabalho. 
eterno - aceitas, recebidas, reconhecidas - em determinados momentos da história, quando esta se abre ao incondicional ${ }^{8}$.

Os outros conceitos dizem respeito à lei superior ou lei da vida. Para a teonomia, trata-se de lei inerente ao ser humano, mas baseada no fundamento divino que é o próprio fundamento do homem. Para a autonomia, o ser humano é sua própria lei enquanto portador da razão universal, fonte e medida da cultura e da religião. Enfim, a heteronomia acredita que o ser humano, incapaz de agir segundo a razão universal, deve se submeter a leis estranhas e superiores a si mesmo.

Aplicando estes conceitos à relação entre religião e cultura, chamamos de autônoma a cultura empenhada em criar formas de vida pessoal e social sem qualquer referência a algo supremo e incondicional, seguindo apenas as exigências da racionalidade técnica e prática. A cultura heterônoma, por sua vez, submete as formas e as leis do pensamento e da ação ao critério da autoridade da religião eclesiástica e da política quase religiosa, mesmo ao preço de destruir as estruturas da racionalidade. A cultura teônoma expressa nas suas criações a preocupação suprema e o sentido transcendental não como algo que lhe seja estranho, mas como seu próprio fundamento espiritual. "A religião é a substância da cultura e a cultura, a forma da religião". Podemos dizer que esta frase define com precisão o que entendemos por teonomia. Estas distinções possibilitaram a criação da análise teônoma da cultura, da "teologia da cultura".

Acreditamos que uma releitura de teologia da cultura de Tillich possa trazer uma contribuição importante à teologia latino-americana, pois esta estabeleceu como seu princípio fundamental e ponto de partida a experiência crítica e libertadora de Deus feita na realidade alienada e ameaçada dos empobrecidos (inclusive culturalmente) e excluídos e a reinterpretação da Boa-Nova do Evangelho em função dessa realidade. Tillich viveu momentos comparáveis ao atual ocaso das utopias sociais, econômicas e políticas e refletiu dentro desse vazio e desse desencanto que sucedem ao desmoronamento das esperanças. O tempo chegou novamente de se dedicar à análise dos fatores esquecidos no entusiasmo da luta. Um deles é a diversidade cultural e religiosa: cultura e religião ligadas à natureza e à história; à tradição passada e à experiência

\footnotetext{
Ver EP, cap. III: Kairos, esp. p. 64 e 73.

9 EP, p. 85.
} 
presente; cultura e religião de mulheres e de homens; do campo e da cidade; de índios, negros, brancos e mestiços; do capitalismo selvagem e do neoliberalismo, etc. O tempo chegou de retomar o projeto de uma teologia da cultura e da enculturação - projeto possível e legítimo assim como Tillich o mostrou em outros tempos e lugares.

Escolhemos alguns exemplos - que apresentaremos a seguir- para ilustrar o projeto tillichiano de teologia da cultura.

\section{Aplicações. Três exemplos de análise religiosa da cultura}

\subsection{Análise da cultura da sociedade industrial}

Lemos na "Teologia da Cultura":

A nossa cultura presente deve ser descrita em função de um movimento predominante e de um protesto sempre mais poderoso contra esse movimento. O espírito do movimento predominante é o espírito da sociedade industrial. $\mathrm{O}$ espírito do protesto é aquele da análise existencial da condição humana ${ }^{10}$.

Conforme o nosso autor, a sociedade industrial nos leva a uma objetivação completa da nossa visão do mundo, que ameaça perder o ser humano no mundo fabricado por ele, mundo de coisas manipuláveis e utilizáveis; a uma estandardização radical da nossa maneira de viver, uma despersonalização trágica da nossa concepção do homem, com a consequência da perda da dimensão de profundidade da nossa existência. A realidade perdeu a sua transparência à eternidade, os símbolos religiosos perderam sua capacidade de evocar a transcendência. O protesto só conseguiu denunciar o vazio das nossas existências sem poder preenchê-lo, colocando pelo menos a questão de um sentido último da vida. As contradições inerentes à sociedade industrial não foram superadas e o homem continua sem saber o verdadeiro sentido da sua vida e do destino da humanidade. Vivemos num mundo de meios que se revela incapaz de satisfazer o mundo dos fins e onde o poder da técnica mostra-se "insuperável e esmagador". Os objetos produzidos tornam-se

10 Paul TILLICH, Theology of Culture, Oxford University Press, New York, 1964, p. 43. Cf. Jean-Paul GABUS, op. cit., p. 49-56. 
coisas desprovidas de qualquer subjetividade; o próprio produtor pode tornar-se uma "coisa" num mundo de coisas.

Fundada na "Nova Realidade" em Cristo, a ação cristã deverá exigir que, na sociedade industrial, a pessoa humana seja tratada como fim - não simples meio ou coisa - e deverá querer mais justiça e igualdade nas estruturas sociais e econômicas, e o fim de toda exploração e opressão. Os processos técnicos também podem tornar-se teônomos e abrir-se a um sentido último. Graças à arte e ao poder sublimado de Eros, os objetos produzidos pelo ser humano podem deixar de ser simples coisas. Podem ser humanizados, reencontrar um verdadeiro significado para o homem, servir novamente como meios para um fim transcendente, ajudar o ser humano a realizar-se como pessoa.

O modo como a modernidade se estabeleceu na América Latina - através de um processo dominador, predador e excludente - só pode reforçar os efeitos negativos do sistema baseado na racionalidade instrumental objetivante ${ }^{11}$. Qualquer tentativa de "modernização" a partir do modelo capitalista industrial deve ficar suspeita; a participação no mercado de capitais produziu a dívida externa; o pretenso "desenvolvimento sustentável" está arriscado a aumentar a devastação do meio ambiente e o saque dos recursos naturais da América Latina.

\subsection{Análise religiosa do capitalismo e do socialismo}

O nosso instrumento de análise é agora o que Tillich chama de "princípio protestante" ou "princípio profético". Esse princípio contém o protesto divino e humano contra qualquer reivindicação absoluta levantada por realidades relativas; ele apresenta-se como juiz de qualquer realidade religiosa e cultural, incluindo a religião e a cultura que se chamam "protestantes"; ele desmascara toda forma de idolatria ou demonização.

Graças ao princípio protestante, Tillich completa a análise da situação do proletariado proposta pelo movimento socialista, no contexto da total dependência do mercado. O princípio protestante afirma que a

11 Ver, por exemplo: Gustavo GUTIERREZ, A força histórica dos pobres. Petrópolis: Vozes, 1981, esp. cap. IV: A partir do reverso da história, p. 243-309; Alfonso GARCÍA RUBIO, Unidade na pluralidade, São Paulo: Paulinas, 1989, cap. 1,3: O Brasil e a civilização industrial: a modernidade vista a partir da periferia, p. 42-56. 
situação humana está basicamente deformada. O elemento trágico na situação humana vem da perversão da nossa natureza ("pecado original"), porque o poder humano de se autodeterminar carrega em si a possibilidade de autodeterminação pervertida e destrutiva. A situação proletária torna-se explicável, em última análise, a partir daí: na situação do proletariado, a perversão da natureza humana mostra a sua realidade no plano da vida social.

O caráter universal do ser humano revela-se na situação do proletariado. Este fato envolve o reconhecimento teológico de que há situações em que a perversão da natureza essencial do ser humano se manifesta principalmente enquanto perversão social e na forma de culpa social; e envolve o reconhecimento filosófico do fato de que a situação proletária, longe de ser mero acidente histórico, representa a distorção da natureza humana essencial e a ruptura demoníaca da humanidade em geral. Dessa forma, os julgamentos decorrentes do princípio protestante e da situação proletária são mutuamente compatíveis. O julgamento protestante se concretiza e se faz real e urgente ao se aplicar à situação das classes sociais hoje em dia; e o julgamento socialista se faz universal, profundo e religiosamente significativo ao se elevar à situação humana geral ${ }^{12}$.

E Tillich prossegue, um pouco mais adiante:

A situação proletária decorre inevitavelmente da estrutura demoníaca do capitalismo. Ninguém, em nossa época, não importando se pertence à burguesia ou grupo proletário, pode escapar das contradições essenciais e permanentes do sistema capitalista. A mais óbvia e a mais fundamental dessas contradições é a luta de classes que está acontecendo em todos os momentos, tanto de cima como de baixo. Ninguém pode evita-la, uma vez que dentro do capitalismo ela faz parte, necessariamente, da luta pela existência ${ }^{13}$.

Podemos aqui remeter às análises do "pecado social ou coletivo" na teologia latino-americana e às aplicações feitas à situação social de miséria e opressão ${ }^{14}$.

\section{EP, p. 186.}

EP, p. 187-188.

4 Por exemplo: Clodovis BOFF, O pecado social, em VV.AA. Comunidade eclesial, comunidade política. Petrópolis: Vozes, 1978, p. 157-184; Francisco MORENO REJÓN, Teologia moral a partir dos pobres. Aparecida, SP: Santuário, 1987, p. 160-178. 
O princípio profético ou protestante, enquanto expressão cultural-religiosa do Ultimate Concern, leva também à crítica da razão utópica no marxismo, do "idealismo" da sociedade sem classes e do Reino da Liberdade como realizações intra-históricas.

O princípio protestante torna possível a compreensão do caráter paradoxal da antecipação [...] e, além disso, pode advertir contra a distorção que ameaça qualquer antecipação que é o utopismo. [...] Todas as antecipações realmente genuínas referem-se a algo que permanece transcendente; situam-se além de qualquer realização concreta do destino humano [...]. No entanto, a transcendência não significa que a realidade deformada não deva ser mudada; bem ao contrário, busca constantemente a transformação revolucionária da situação existente. A antecipação proletária envolve uma mudança real na existência proletária que significa a destruição e superação do capitalismo. Mas não pretende fazer surgir uma situação totalmente livre das ameaças que sempre confrontam a existência humana ${ }^{15}$.

Não podemos deixar de reproduzir ainda um trecho particularmente profético de 1931, contra toda fixação dogmática de um modelo revolucionário: é impossível imobilizar a dialética histórica!

O proletariado corre constantemente o perigo de abandonar a "vocação" da luta pela extinção da sociedade de classes. [...] Mesmo se for preciso substituir o proletariado por algum outro instrumento do destino, a dialética fundamental da história permanecerá inalterada em sua essência. [...] Assim, o protestantismo ser rejeitado sob o julgamento do seu próprio princípio, se não responder a essa vocação positivamente. O mesmo se dá com o proletariado. Se não se mantiver fiel na luta para derrubar a estrutura demoníaca do capitalismo, será necessariamente rejeitado em virtude da própria "vocação"16.

$\mathrm{Na}$ teologia da libertação latino-americana, antes e depois da queda - real e simbólica - do muro de Berlim, está em curso uma revisão do juízo teológico sobre o socialismo (real e utópico) que deve muito àquilo que pensadores "revisionistas" como Tillich, Bloch ou Mannheim escreveram nos anos vinte e trinta ${ }^{17}$.

15 EP, p. 191.

16 EP, p. 192-193.

17 Ver, por exemplo: Franz HINKELHAMMERT, Crítica a la razón utópica. San José: DEI, 1984; Clodovis BOFF, Otto MADURO e outros, Teologia da libertação: novos desafios. São Paulo: Paulinas, 1991; Clodovis BOFF, A implosão do socialismo autoritário e a 


\subsection{Natureza, símbolo e sacramento}

Paul Tillich pleiteia a revalorização do elemento sacramental dentro do protestantismo e o respeito do elemento natural do sacramento - que mantém uma relação essencial com o mesmo ${ }^{18}$. Assim, em virtude de seu poder natural, a água pode tornar-se, adequadamente, portadora do poder sacro e transformar-se, desse modo, em elemento sacramental do batismo. Até a palavra apoia-se num elemento natural (sopro, som).

Tillich parte do conceito material de natureza, que contrasta o natural com todas as coisas envolvidas com liberdade, especialmente o espírito e a história. Nesse sentido, a natureza é portadora de significado e poder sacramentais.

A interpretação mágica da natureza - o poder natural das coisas contém ao mesmo tempo o poder sagrado - foi desfeita pelas atitudes racionais-objetivas. A partir da física matemática e do controle técnico da natureza, a mesma passa a ser controlada, objetivada e destituída de suas qualidades. Só subsiste o aspecto quantitativo. A natureza se torna incapaz de carregar o poder transcendente, por exemplo, através de símbolos naturais como a água, o fogo, a luz, o vento, as árvores, as pedras e as montanhas. Ao contrário, a filosofia vitalista da natureza (Nietzsche) reconhece o poder da natureza, mas trata-se de um poder sem significado, sem intencionalidade. Por sua vez, a interpretação romântico-simbólica da natureza quer devolver-lhe o seu caráter qualitativo, sua profundeza e seu sentido, ao interpretá-la como símbolo do espírito. Mas este ponto de vista é pouco consciente das estruturas reais da natureza, apenas acrescenta a imaginação subjetiva à "natureza" calculável da física.

Diante da insuficiência de todas essas interpretações, Tillich propõe um "novo realismo":

O poder e o sentido da natureza devem ser buscados dentro e por meio de suas estruturas objetivas físicas. Na natureza, o poder e o caráter físico não se separam das estruturas significativas e objetivas. O poder da

teologia da libertação, em REB 50 (1990), p. 76-92; Revista de Cultura Vozes 84 (1990), $\mathrm{n}^{\mathrm{o}} 4$ etc.

18 Quando falamos em natureza, trata-se evidentemente da natureza incorporada à cultura, assumida e transformada por ela. Nesse sentido, a teologia da natureza é um aspecto da teologia da cultura. 
natureza deve ser encontrado na esfera que antecede a separação entre subjetividade e objetividade em nosso mundo ${ }^{19}$.

Só assim chegaremos a uma estrita compreensão do caráter indireto e simbólico dos termos usados na descrição do poder e do significado da natureza. Por outro lado, nenhum sacramento, no pensamento cristão, pode ser entendido sem referência ao novo ser em Jesus, o Cristo, e, consequentemente, sem referência à história. A natureza, ao ser adaptada ao uso sacramental do cristianismo, deve ser entendida historicamente e no contexto da história da salvação. Quando se interpreta a natureza desta maneira realista e, ao mesmo tempo, histórica, os objetos naturais transformam-se em portadores do poder e do sentido transcendentais e podem ser usados como elementos sacramentais.

Entre os exemplos dados para ilustrar essa teoria, Tillich fala do poder dos números, dos elementos da natureza inorgânica (como os quatro elementos da filosofia grega e as pedras "preciosas"), da luz e das cores como expressões da transcendência, do poder da vida vegetal (árvores) e dos animais - com seu aspecto trágico e demoníaco -, do sentido e do poder do corpo humano - no qual se concentram todas as potências da natureza, transcendendo as formas inferiores para chegar ao nível da liberdade e da história; enfim, de situações e configurações da natureza (astrologia); de ritmos naturais que adquiriram poder sagrado; e da "palavra", que é o processo natural mais importante para a atitude protestante em face da natureza. E conclui: "A desvalorização religiosa da natureza tem provocado a desvalorização naturalista (ou positivista) da religião" 20 .

Essa reflexão toda sobre o poder sacramental da natureza apoia-se numa teoria do símbolo e da linguagem religiosa como linguagem simbólica:

Os símbolos religiosos valem-se da realidade finita para expressar a nossa relação com o infinito. Mas essa realidade finita que utilizam não é simples meio arbitrário para se chegar a determinado fim, algo que lhe seria estranho; ela participa no poder da realidade suprema a que se refere.

19 EP, p. 128.

20 EP, p. 134. 
Os símbolos religiosos têm sempre dois lados. Expressam não só a coisa simbolizada, mas também o elemento empregado nessa simbolização ${ }^{21}$.

Podemos dar o exemplo da cura, da saúde, que podem - numa cultura teônoma - simbolizar a salvação, entendida como cura final cósmica e individual. Por outro lado, os símbolos nascem e morrem, em função de mudanças na situação humana. Assim, embora qualquer realidade natural ou cultural possa servir, em princípio, para simbolizar o Incondicionado, há símbolos tradicionais do cristianismo ou das religiões que se encontram, hoje, desqualificados, definitiva ou provisoriamente. Numa nova teonomia (que só poderá manifestar-se num momento propício ou kairos em grande parte imprevisível), símbolos esvaziados podem renascer, assim como podem ser criados novos símbolos significantes.

A partir da revalorização do simbolismo natural do transcendente, abre-se um campo imenso para a preservação da natureza contra seus predadores tecnocientíficos ("integridade da criação", conforme o Conselho Mundial de Igrejas), para uma espiritualidade do meio-ambiente e para uma "democracia cósmica" (Leonardo Boff); para a superação da racionalidade puramente instrumental e quantitativa na linguagem científica: "gnose de Princeton", movimento ecológico, busca de um novo paradigma cosmológico, biológico, antropológico ${ }^{22}$; também para uma abertura e um diálogo com as religiões que privilegiam o encontro com o sagrado na natureza, como as religiões indígenas e afro-americanas; enfim, pode ser superada a oposição entre um catolicismo popular marcado pelo ritmo natural das estações, do dia e da noite, dos ciclos solares e lunares e um cristianismo libertador, centrado na luta histórica que segue a linha do progresso linear ascendente. É o que o kairos atual exige de nós.

$21 \quad$ EP, p. 89.

22 Ver Jean-Pierre Dupuy, Ordres e désordres, enquête sur un nouveau paradigme. Paris : Seuil, 1982. O autor se refere a pensadores como Henri Atlan, Ilya Prigogine, Francisco Varela, René Girard, Edgar Morin, Cornélius Castoriadis, Ivan Illich etc. 


\section{Conclusão: sobre a possibilidade e legitimidade de uma teologia da cultura}

Esses exemplos mostraram que a dimensão divina ou transcendente da realidade transformada pela cultura pode ser alcançada pela teologia, pois há uma correlação ou interdependência entre a fé e a realidade, correlação fundamentada na repercussão universal do evento cristológico. A teologia da cultura - sempre contextualizada ou "em situação" - faz toda teologia querigmática ou dogmática lembrar-se de que a Palavra de Deus só se dirige ao ser humano numa situação concreta, histórica e culturalmente condicionada. Por isso, a teologia necessita, para realizar-se concretamente, do auxílio das outras ciências humanas e da filosofia, que fornecerão não apenas sua conceitualidade e metodologia, mas também o material de sua própria reflexão. Por outro lado, a teologia da cultura coloca uma série de questões ineludíveis à reflexão dogmática atual, como o significado da autonomia humana, o sentido da história e das lutas históricas, o significado teológico da civilização capitalista industrial urbana e da sua crise, o sentido da crise ecológica e da presença do divino na natureza etc.

Interpretando o evento cristológico como a manifestação em Jesus, o Cristo, de uma Realidade Nova (um Novo Ser) que supera a alienação e as ambiguidades da vida humana, a teologia tillichiana preserva a substância e a originalidade da mensagem cristã. Afirmando que o poder de cura e de salvação do Novo Ser age (de modo não ambíguo, mas fragmentário) na comunidade cristã, mas também no mundo dos homens, Tillich situa essa mensagem na sua plena dimensão cósmica, universal e escatológica. Evitando, a um tempo, o fundamentalismo e a perda da identidade cristã, a teologia da cultura de Paul Tillich sugere uma via média, porém audaciosa, corajosa e estimulante para o testemunho da Igreja no mundo de hoje.

No momento em que a problematização da luta social e política enriquece-se da dimensão da cultura e da "enculturação" - isso ficou claro em acontecimentos recentes como o $8^{\circ}$ Encontro Intereclesial de CEBs, a Assembleia do Povo de Deus em Quito e a Assembleia do CELAM em Santo Domingo - a reflexão tillichiana nos convida a superar todo dogmatismo totalitário, seja ele de cunho restaurador ou revolucionário, para abrir-nos à riqueza infinita do Amor, manifestada 
na imensidão da Criação e na solidariedade humana. Na hora em que as sociedades modernas sufocam debaixo do descartável e do consumível que elas produzem, Tillich chama a nossa atenção para a exigência incondicional de salvar a vida ameaçada dos sem-terra, sem-teto, sem-emprego, sem-valor. Essa exigência se faz ver em toda cultura ou religião, aos olhos abertos de um ecumenismo sem fronteiras. Pois todo ser humano recebeu do Criador o poder inaudito de decifrar os símbolos. 